\title{
Prostaglandin E2 serves a dual role in regulating the migration of dendritic cells
}

\author{
GE DIAO* , JIE HUANG ${ }^{*}$, XIUHUI ZHENG, XINWEI SUN, MIN TIAN, JIAN HAN and JIANXIN GUO \\ Department of Gynecology and Obstetrics, Daping Hospital, Army Medical University \\ (Third Military Medical University), Chongqing 400042, P.R. China
}

Received July 8, 2020; Accepted November 4, 2020

DOI: $10.3892 /$ ijmm.2020.4801

\begin{abstract}
Dendritic cells (DCs) are the most potent antigen-presenting cells, and are indispensable in the immune system. Prostaglandin E2 $\left(\mathrm{PGE}_{2}\right)$ has been demonstrated to modulate the migration of DCs, but with inconsistent results. The present study, based on our previous research, used murine bone marrow-derived DCs to elucidate the potential regulatory mechanism of $\mathrm{PGE}_{2}$ on the migration of DCs. The results indicated that $\mathrm{PGE}_{2}$ served a dual role in regulating the migration of DCs in a dose-dependent manner. High concentrations of $\mathrm{PGE}_{2}$ inhibited cell migration, whereas low concentrations exhibited the opposite effect. Flow cytometry revealed that the expression of CC chemokine receptor type 7 on the DC surface was increased following treatment with low concentrations of $\mathrm{PGE}_{2}$ and slightly decreased by high concentrations of $\mathrm{PGE}_{2}$. The effect of $\mathrm{PGE}_{2}$ was indicated to be exerted via reorganizing the F-actin cytoskeleton using confocal microscopy. Moreover, the regulatory effect of $\mathrm{PGE}_{2}$ on the migration of DCs was validated in vivo. Subsequent gene expression profile analyses using RNA-sequencing technology indicated that $\mathrm{PGE}_{2}$ induced alterations in the expression of multiple downstream genes and signaling pathway molecules associated with cell migration and the cytoskeleton. These findings may provide an improved understanding on the mechanism of DC migration under both pathological and physiological conditions. Moreover, the biological implications of these findings may provide a novel perspective of the immunological surveillance in the progression of different types of diseases.
\end{abstract}

Correspondence to: Professor Jianxin Guo or Professor Jian Han, Department of Gynecology and Obstetrics, Daping Hospital, Army Medical University (Third Military Medical University), 10 Changjiangzhilu Street, Yuzhong, Chongqing 400042, P.R. China E-mail: guojianxinguo@163.com

E-mail: hj_obgyn@tmmu.edu.cn

${ }^{*}$ Contributed equally

Key words: prostaglandin E2, dendritic cells, cell migration, dual role, RNA-sequencing

\section{Introduction}

Dendritic cells (DCs) serve a critical role in coordinating immune responses. The main function of DCs is to search their environment for foreign antigens and present these antigens on their cell surface to $\mathrm{T}$ cells. They also act as messengers between the innate and the adaptive immune system (1). Once activated by injury or inflammatory stimuli, DCs migrate to the lymph nodes and stimulate $\mathrm{T}$ cells to differentiate and commence a robust immune response (2). Therefore, maintaining the normal migratory ability of DCs is crucial for the normal function of the body's immune system. However, the pathogenesis of numerous types of diseases, including chronic myelocytic leukemia and several other types of cancers, has been attributed to the deteriorated migratory ability of DCs $(3,4)$. For example, a previous study reported that endometrial and cervical tumors were capable of inhibiting DC migration from the lesion tissue to the draining lymph node, which subsequently promoted the immune evasion of the tumors (5). Therefore, it is important to determine the factors that may affect the migration of DCs.

Prostaglandin E2 $\left(\mathrm{PGE}_{2}\right)$ is generated by the cyclooxygenase conversion of arachidonic acid, which is released from membrane phospholipids, modulating various pathological and physiological processes (6). Moreover, $\mathrm{PGE}_{2}$ has been demonstrated to be a key modulator of DC function, including the ability to regulate the migration of DCs (7). However, the existing data regarding the role of $\mathrm{PGE}_{2}$ are controversial. Several reports have suggested that $\mathrm{PGE}_{2}$ may improve the migratory ability of DCs (8-10). On the other hand, a few studies, including our previous study, have provided contradictory results, suggesting an inhibitory role of $\mathrm{PGE}_{2}$ in $\mathrm{DC}$ migration $(11,12)$. Therefore, it remains a priority to clarify the regulatory mechanism of $\mathrm{PGE}_{2}$ on the migratory ability of DCs.

The present study used murine bone marrow-derived DCs (BMDCs) to clarify the modulatory mechanism of $\mathrm{PGE}_{2}$ on the migratory ability of DCs. The results of the current study may provide an improved understanding on the mechanism of DC migration under both pathological and physiological conditions. Furthermore, the biological implications of these findings may provide a different perspective of the immunological surveillance in the progression of several types of diseases. 


\section{Materials and methods}

Cell culture. The animal studies were approved by the Research Council and Animal Care and Use Committee of the Research Institute of Surgery, Daping Hospital, Third Military Medical University (Chongqing, China). All experiments conformed to the guidelines of ethical use of animals, and all efforts were made to minimize animal suffering and reduce the number of animals used. DCs were isolated from mouse bone marrow as previously described with slight modifications $(13,14)$. C57BL/6 mice (male; age, 6-8 weeks; weight, $20-25 \mathrm{~g}$; $\mathrm{n}=40$ ) were provided by the Experimental Animal Center of Daping Hospital, Third Military Medical University. Mice were maintained in a specific pathogen-free environment at $22 \pm 2^{\circ} \mathrm{C}$ with $55 \pm 5 \%$ humidity under a 12 -h light/dark cycle. Food and water were provided ad libitum. The health and behavior of the animals were monitored once every morning and afternoon. The mice were sacrificed by cervical dislocation. Death was confirmed by the lack of pulse, breathing, corneal reflex, response to toe pinch, respiratory sounds and heartbeat. Briefly, bone marrow cells were flushed out from the femurs and tibias of mice with a 1-ml syringe filled with RPMI-1640, and red cells were subsequently removed using erythrocyte lysis fluid (Beyotime Institute of Biotechnology). The remaining cells were cultured in RPMI-1640 supplemented with 10\% FBS (both from Gibco; Thermo Fisher Scientific, Inc.), $100 \mathrm{U} / \mathrm{ml}$ penicillin, $100 \mu \mathrm{g} / \mathrm{ml}$ streptomycin, $20 \mathrm{ng} / \mathrm{ml}$ recombinant granulocyte-macrophage colony-stimulating factor and IL-4 (both from PeproTech, Inc.). Cells were cultured at $37^{\circ} \mathrm{C}$ in an atmosphere containing $5 \% \mathrm{CO}_{2}$. On day 3 , non-adherent granulocytes were gently removed, and fresh media were added. On day 7 , the immature DCs were stimulated with $1 \mu \mathrm{g} / \mathrm{ml}$ LPS (MilliporeSigma) for $24 \mathrm{~h}$. On day 8, mature DCs were collected. In subsequent experiments, mature DCs were treated with different concentrations of $\mathrm{PGE}_{2}$ for $24 \mathrm{~h}$.

Transwell migration assay. The lower chambers of 24-well Transwell plates $(8.0 \mu \mathrm{m}$ pore size; MilliporeSigma) were filled with $600 \mu \mathrm{l}$ serum-free RPMI-1640 medium including C-C motif chemokine 19 (CCL19; $100 \mathrm{ng} / \mathrm{ml}$; PeproTech, Inc.). DCs $\left(1 \times 10^{5}\right.$ cells in $\left.0.1 \mathrm{ml}\right)$ resuspended in serum-free RPMI-1640 medium were seeded in the upper chambers of the Transwell plates and allowed to migrate for $3 \mathrm{~h}$ at $37^{\circ} \mathrm{C}$ in $5 \% \mathrm{CO}_{2}$. The numbers of migrated DCs that were harvested from the medium of the lower chambers were counted with a hemocytometer under an inverted microscope (DMi8; Leica Microsystems GmbH; magnification, x100).

$3 D$ migration assay. DCs were mixed with a collagen matrix (BD Matrigel; BD Biosciences; final concentration $1.7 \mathrm{mg} / \mathrm{ml}$; $4.5 \times 10^{5}$ cells $/ \mathrm{ml} ; 45 \mu 1$ cells/well) in migration chambers (cat. no. 70326-10; CoverWell ${ }^{\mathrm{TM}}$ Perfusion Chamber; Electron Microscopy Sciences). Theremaining space of the chambers was filled with RPMI-1640 medium containing $200 \mathrm{ng} / \mathrm{ml} \mathrm{CCL19.}$ Migration of DCs was recorded by bright-field time-lapse video microscopy at $37^{\circ} \mathrm{C}$, which started $10 \mathrm{~min}$ after cell injection, using inverted microscopes (Observer Z1; Zeiss $\mathrm{GmbH}$; magnification, x100) fitted with $10 x$ objectives and Axiocam cameras (Zeiss $\mathrm{GmbH}$ ). Cells were imaged at a frame rate of
2 min up to 61 frames. Computer-assisted cell tracking was performed with custom software (ImageJ v1.46r bundled with 64-bit Java v1.6.0_20; National Institutes of Health). The average speed was calculated as the step length per minute for each cell. A total of 30 randomly selected cells were included in one experiment.

Flow cytometry. DCs $\left(1 \times 10^{6}\right)$ were blocked for $15 \mathrm{~min}$ at $4^{\circ} \mathrm{C}$ with PBS containing 0.5\% BSA (MilliporeSigma), and subsequently incubated with the respective antibodies for $30 \mathrm{~min}$ at $4^{\circ} \mathrm{C}$. After being washed twice with PBS, the cells were resuspended in $200 \mu \mathrm{l}$ PBS. The antibodies used included phycoerythrin-conjugated anti-mouse CD40 (1:100; cat. no. 12-0401), CD80 (1:100; cat. no. 12-0801), CD86 (1:100; cat. no. 12-0862), major histocompatibility complex II (MHCII; 1:100; cat. no. 12-5321) and C-C chemokine receptor type 7 (CCR7; 1:100; cat. no. 12-1971; all from eBioscience; Thermo Fisher Scientific, Inc.). FACS analysis was performed on a FACSCalibur flow cytometer using CellQuest Pro software (version 6.0; BD Biosciences).

Western blotting. Western blotting was used to determine the protein expression level. After treatment with different concentrations of $\mathrm{PGE}_{2}$, cell lysates were prepared by collecting DCs in the cell lysis buffer for Western or IP (cat. no. P0013; Beyotime Institute of Biotechnology). Protein concentration was determined using BCA Protein Assay kit (cat. no. 23227; Thermo Fisher Scientific, Inc.). Cell lysates containing equal amounts of protein (30-50 $\mu \mathrm{g})$ were subjected to a $10 \%$ SDS-PAGE. Proteins were transferred to nitrocellulose membranes and subsequently blocked in TBS- $0.05 \%$ Tween- 20 buffer containing 5\% BSA (MilliporeSigma). The membranes were incubated with antibodies against phospho-paxillin (Tyr118) (1:1,000; cat. no. orb14813; Biorbyt Ltd.), paxillin (1:1,000; cat. no. orb89537; Biorbyt Ltd.) and GAPDH (1:2,000; cat. no. 60004-1-Ig; ProteinTech Group, Inc.) overnight at $4^{\circ} \mathrm{C}$. Following incubation with HRP-conjugated goat anti-mouse (1:1,000; cat. no. SA00001-1; ProteinTech Group, Inc.) or goat anti-rabbit (1:1,000; cat. no. A0208; Beyotime Institute of Biotechnology) secondary antibody at room temperature for $1 \mathrm{~h}$, immunoreactivities were detected using SuperSignal ${ }^{\mathrm{TM}}$ West Pico PLUS Chemiluminescent Substrate (cat. no. 34577; Thermo Fisher Scientific, Inc.). Densitometric analysis was performed using ImageJ software (ImageJ v1.46r bundled with 64-bit Java v1.6.0_20; National Institutes of Health) with protein expression levels normalized to GAPDH.

Immunofluorescence detection of F-actin cytoskeleton. DCs $\left(1 \times 10^{6}\right)$ were seeded on the coverslips coated with poly-L-Lysine and incubated at $37^{\circ} \mathrm{C}$ overnight. The cells were subsequently fixed with $4 \%$ paraformaldehyde at $4{ }^{\circ} \mathrm{C}$ for $15 \mathrm{~min}$, permeabilized with $0.1 \%$ Triton X-100 at room temperature for $5 \mathrm{~min}$ and incubated with $1 \% \mathrm{BSA}$ at room temperature for $30 \mathrm{~min}$. To detect F-actin, the cells were stained with a FITC-phalloidin solution (5 $\mu \mathrm{g} / \mathrm{ml}$ in 1\% BSA-PBS; MilliporeSigma) for $45 \mathrm{~min}$ at room temperature. Subsequently, the cells were counterstained with DAPI for $5 \mathrm{~min}$ at room temperature. Fluorescent images were acquired using confocal microscopy (magnification, $\mathrm{x} 400$ ).

In vivo migration assay. C57BL/6 mice ( $\mathrm{n}=5$ per group; male; age, 4- 6 weeks; weight, 20-25 g) provided by the Experimental 

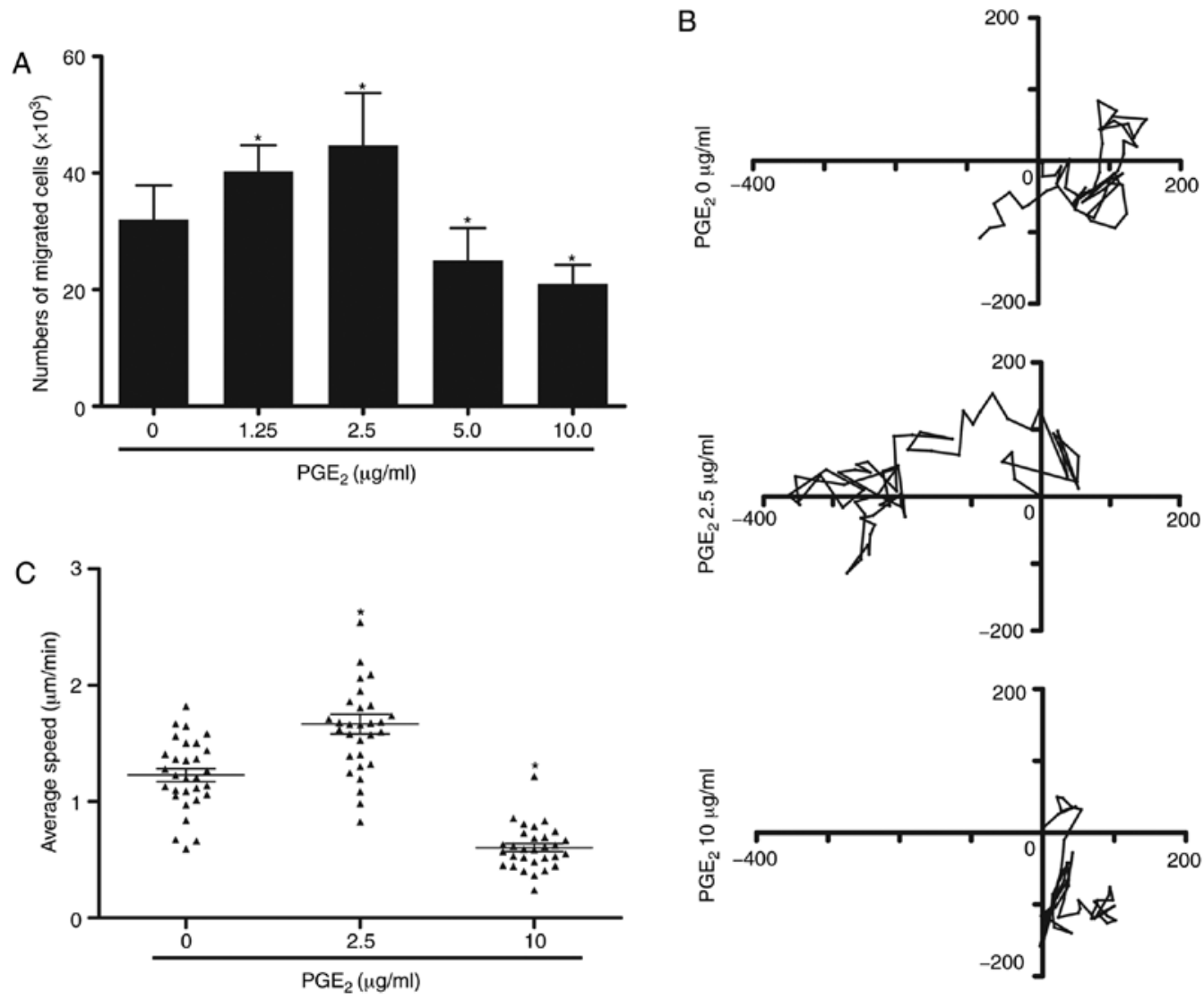

Figure 1. DC migration is modulated by $\mathrm{PGE}_{2}$. (A) The migratory capability of DCs was determined by Transwell migration assay. Data are representative of five independent experiments and are presented as the mean \pm SEM. $P<0.05 \mathrm{vs.} 0 \mu \mathrm{g} / \mathrm{ml} \mathrm{PGE}$. (B) Tracks of individual DCs detected in $3 \mathrm{D}$ migration assay after treatment with $\mathrm{PGE}_{2}$. (C) Migratory capability of DCs determined by $3 \mathrm{D}$ migration assay. Data are representative of three independent experiments and are presented as the mean \pm SEM. P $<0.05$ vs. $0 \mu \mathrm{g} / \mathrm{ml} \mathrm{PGE}_{2}$. DC, dendritic cell; $\mathrm{PGE}_{2}$, prostaglandin E2.

Animal Center of Daping Hospital, Third Military Medical University, were maintained as aforementioned. The mice were injected in the left footpad with $1 \times 10^{6}$ labeled DCs. DCs were labeled with Qtracker ${ }^{\mathrm{TM}} 705$ cell labeling kit (Thermo Fisher Scientific, Inc.) according to the manufacturer's instructions. Animals injected with PBS were used as controls. The experimental protocol lasted $48 \mathrm{~h}$ and no mice died during the protocol. The mice were sacrificed by cervical dislocation as aforementioned. The numbers of labeled DCs collected from inguinal and popliteal lymph nodes were determined by FACS. FACS analysis was performed on a FACSCalibur flow cytometer using CellQuest Pro software (version 6.0; BD Biosciences). For the detection of labeled DCs in dissected tissues, the lymph nodes of mice were dissected $48 \mathrm{~h}$ after injection of DCs, embedded in Tissue-Tek OCT compound (Sakura Finetek USA, Inc.) and frozen in liquid nitrogen. Cryosections $(8 \mu \mathrm{m})$ were cut using a cryostat (Leica Microsystems $\mathrm{GmbH}$ ). The sections were dried and frozen at $-20^{\circ} \mathrm{C}$ before use. The slides were fixed with acetone $\left(15 \mathrm{~min} ; 4^{\circ} \mathrm{C}\right)$ and counterstained with DAPI $(5 \mathrm{~min}$; room temperature). Following washing with PBS, the slides were mounted in 50\% glycerol (in PBS) and examined using fluorescence microscopy (magnification, $\mathrm{x} 400$ ).

RNA-sequencing (RNA-seq) analysis. Total RNAs of DCs treated with $0,2.5$ and $10 \mu \mathrm{g} / \mathrm{ml} \mathrm{PGE}$ for $24 \mathrm{~h}$ were extracted using TRIzol ${ }^{\circledast}$ Reagent (Thermo Fisher Scientific, Inc.) according to the manufacturer's instructions. Qubit RNA Assay Kit and Qubit 2.0 Fluorometer (Thermo Fisher Scientific, Inc.) were used to quantify the extracted RNA. Sequencing libraries of mRNA were constructed using Hieff NGS ${ }^{\mathrm{TM}}$ MaxUp Dual-mode mRNA Library Prep Kits for Illumina ${ }^{\circledR}$ (Shanghai Yeasen Biotechnology Co., Ltd.). mRNA was purified from total RNA using Oligo dT magnetic beads. The mRNA was reversely transcribed to double-stranded cDNA (dscDNA). The dscDNA was repaired with phosphate and stickiness $A$ at the two ends ( $5^{\prime}$ and $\left.3^{\prime}\right)$, and then ligated with a DNA adaptor at the 3 '-end. The amplification products were purified using Hieff NGS ${ }^{\mathrm{TM}}$ DNA Selection Beads (Shanghai Yeasen Biotechnology Co., Ltd). The obtained library products were sequenced with a pair end 150 base pair strategy using the Illumina NovaSeq6000 platform (Illumina, Inc.). Gene expression profiles were analyzed by Sangon Biotech Co., Ltd. Genes with $>1.2$-fold changes in their expression were considered as differentially expressed genes. All unique genes were functionally annotated by searching against the National Center for Biotechnology Information NR or NT database (http://www.ncbi.nlm.nih.gov/), Gene Ontology (GO) database (http://www.geneontology.org/) and Kyoto Encyclopedia of Genes and Genomes (KEGG) database (http://www.genome. $\mathrm{jp} /$ ). The Q-values of the GO and KEGG analysis were calculated, and $\mathrm{Q}<0.05$ was considered to indicate a statistically significant difference. The mouse reference genome data from the Ensembl database (http://www.ensembl.org/) were used. 
A
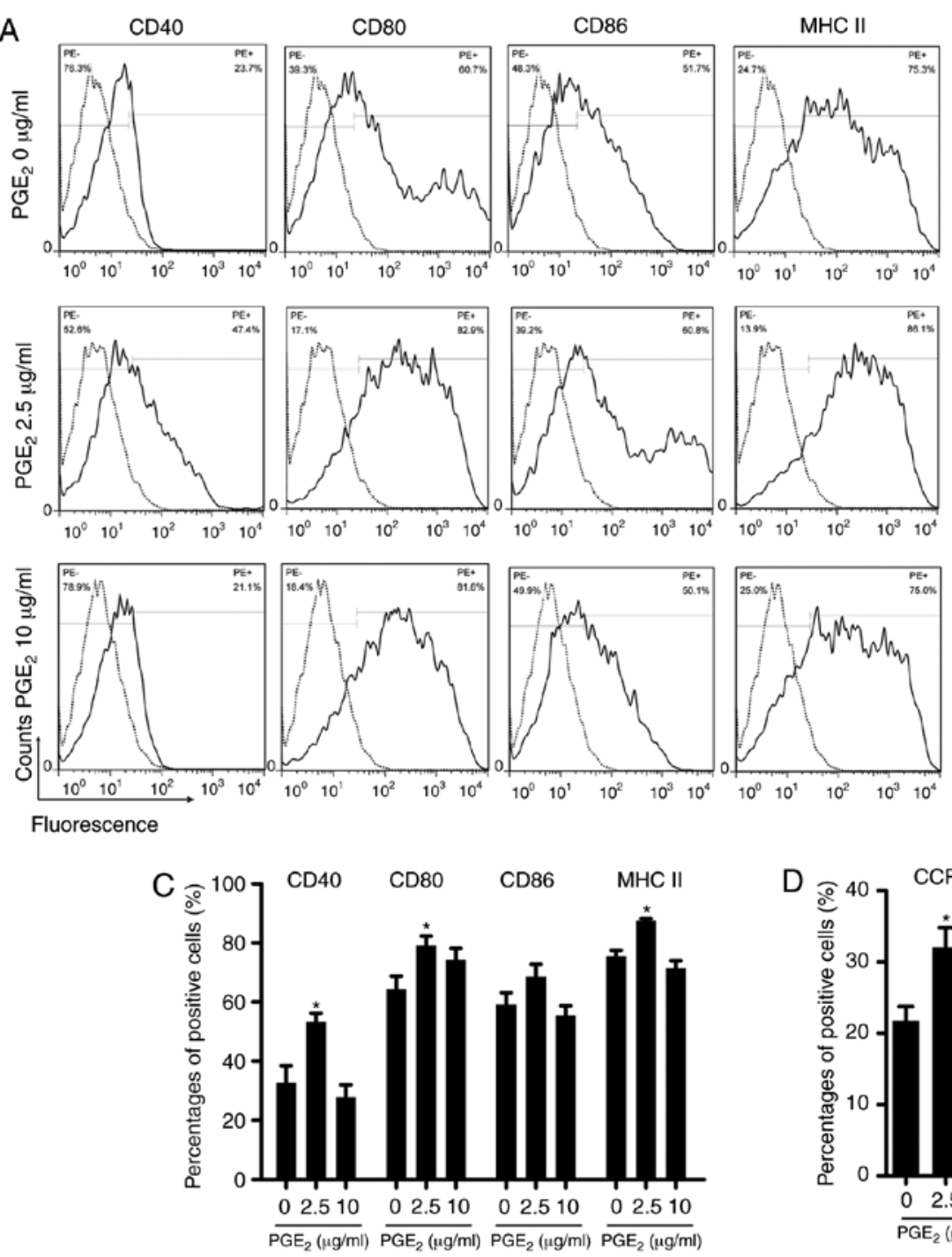

B
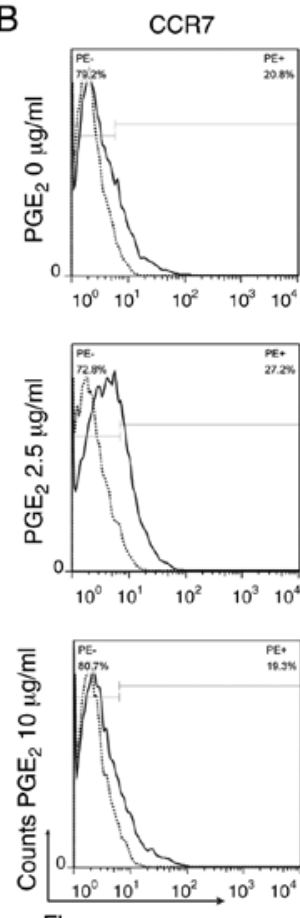

Fluorescence

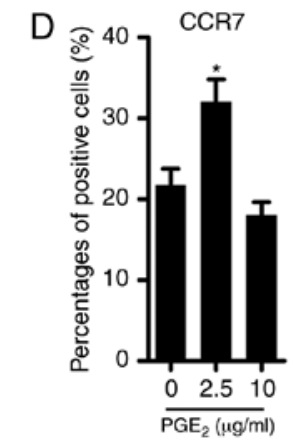

Figure 2. Effect of $\mathrm{PGE}_{2}$ on the expression of surface molecules of DCs determined by flow-cytometry. The numbers at the upper right corner of each plot indicate the percentage of positive cells. (A) Expression of costimulatory markers (CD40, CD80, CD86 and MHC II) on DCs. (B) CCR7 expression on DCs. Bar charts demonstrating the expression of (C) costimulatory markers (CD40, CD80, CD86 and MHC II) and (D) CCR7 on DCs. Data are representative of three independent experiments and are presented as the mean \pm SEM. ${ }^{*} \mathrm{P}<0.05 \mathrm{vs} .0 \mu \mathrm{g} / \mathrm{ml} \mathrm{PGE}_{2}$. DC, dendritic cell; $\mathrm{PGE}$, prostaglandin E2; MHC, major histocompatibility complex; CCR7, CC chemokine receptor type 7.

Statistical analysis. Histogram and scatter graphs were generated using GraphPad Prism v5 software (GraphPad Software, Inc.) and data are presented as the mean \pm SEM. Differences between multiple groups were analyzed by one-way ANOVA followed by Dunnett's post hoc test using IBM SPSS Statistics v19 software (IBM Corp.) $\mathrm{P}<0.05$ was considered to indicate a statistically significant difference.

\section{Results}

$P G E_{2}$ serves a dual role in the migration of DCs. To determine the effect of $\mathrm{PGE}_{2}$ on cell migration, gradient concentrations of $\mathrm{PGE}_{2}$ were added to the culture medium of DCs. The migratory ability of DCs was determined by a Transwell migration assay. According to the results, the concentrations of $\mathrm{PGE}_{2}$ were divided into two different groups. As depicted in Fig. 1A, lower concentrations of $\mathrm{PGE}_{2}(1.25-2.5 \mu \mathrm{g} / \mathrm{ml})$ promoted cell migration, while the migratory ability of DCs was significantly inhibited following treatment with higher concentrations of
$\mathrm{PGE}_{2}(5-10 \mu \mathrm{g} / \mathrm{ml})$ compared with cells treated with $0 \mu \mathrm{g} / \mathrm{ml}$ $\mathrm{PGE}_{2}$. As 2.5 and $10 \mu \mathrm{g} / \mathrm{ml} \mathrm{PGE}_{2}$ demonstrated the highest effect on the migratory ability, these doses were selected to treat DCs in subsequent experiments. A 3D migration assay was subsequently used to validate these findings. Time-lapse video analysis was applied to observe the migration of individual DCs. High concentration of $\mathrm{PGE}_{2}$ significantly inhibited DC migration, whereas low concentration exhibited the opposite effect compared with cells treated with $0 \mu \mathrm{g} / \mathrm{ml} \mathrm{PGE}_{2}$ (Fig. 1B and $\mathrm{C}$ ). These findings suggested that $\mathrm{PGE}_{2}$ may serve a dual role in modulating the migration of DCs.

$P G E_{2}$ affects the expression of surface molecules on DCs. Following stimulation with $2.5 \mu \mathrm{g} / \mathrm{ml} \mathrm{PGE}_{2}$, the expression of several co-stimulatory molecules on the surface of the DCs, such as CD40, CD80 and MHC II, was significantly increased (Fig. 2A and C). The expression of CD86 was also increased, but it was not statistically significant. Treatment with $10 \mu \mathrm{g} / \mathrm{ml}$ $\mathrm{PGE}_{2}$ decreased the expression of all molecules except for 
A
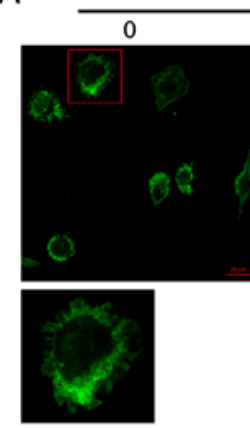

$\mathrm{PGE}_{2}(\mu \mathrm{g} / \mathrm{ml})$
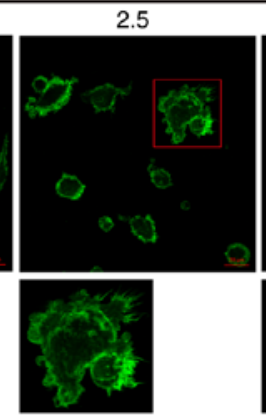

B

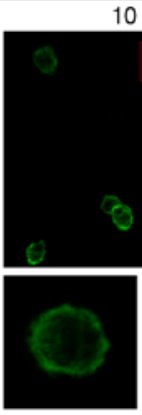

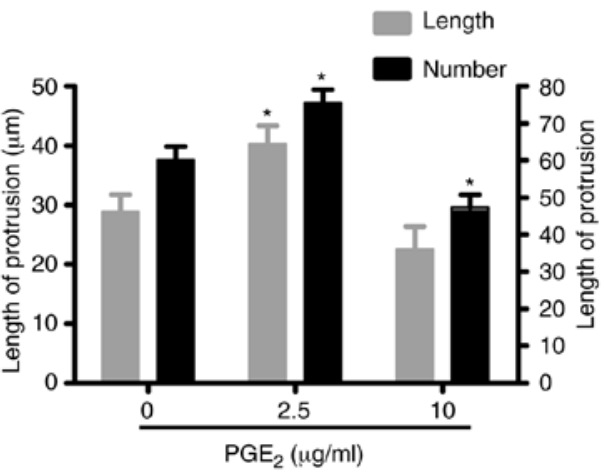
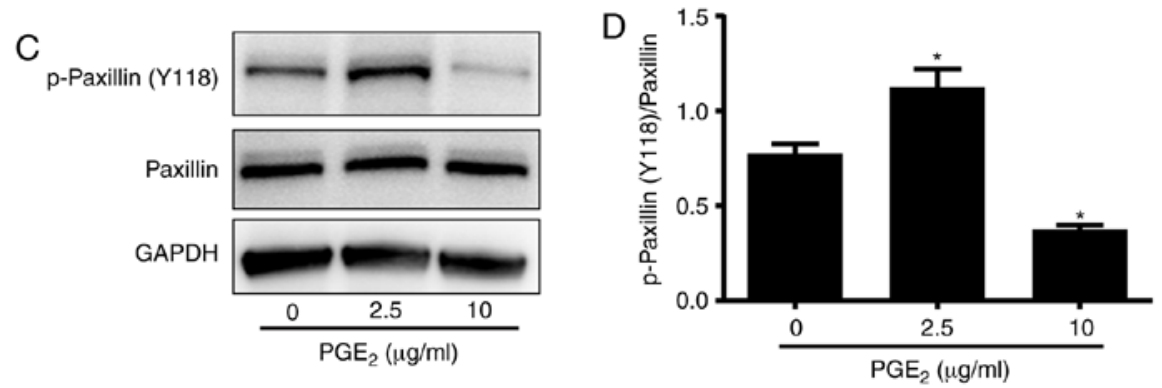

Figure 3. $\mathrm{PGE}_{2}$ induces cytoskeletal reorganization in DCs. (A) Confocal microscope analysis of F-actin organization of DCs treated with different concentrations of $\mathrm{PGE}_{2}$ (original magnification, x400; scale bars, $20 \mu \mathrm{m}$ ). F-actin was stained with FITC-labeled phalloidin (green). (B) Quantification of filopodia on the surface of DCs treated with different concentrations of $\mathrm{PGE}_{2}$. The grey columns represent the length of the filopodia, while the black columns represent the density of the filopodia. Data are representative of three independent experiments and are presented as the mean $\pm \mathrm{SEM}$. ${ }^{*} \mathrm{P}<0.05 \mathrm{vs} .0 \mu \mathrm{g} / \mathrm{ml} \mathrm{PGE}_{2}$. (C) Protein expression levels of paxillin phosphorylated at Tyr118 and total paxillin detected by western blotting. (D) Bar charts demonstrating the quantification of the ratio of p-paxillin/total paxillin. Data are representative of three independent experiments and are presented as the mean $\pm \mathrm{SEM}$. "P<0.05 vs. $0 \mu \mathrm{g} / \mathrm{ml} \mathrm{PGE}_{2}$. $\mathrm{DC}$, dendritic cell; $\mathrm{PGE}_{2}$, prostaglandin E2; p, phosphorylated.

that of CD80, which was unexpectedly increased, although not statistically significant. Since CCR7 is required for the migration of DCs (9), the surface expression of CCR7 was also analyzed (Fig. 2B and D). The expression of CCR7 was significantly upregulated following treatment with $2.5 \mu \mathrm{g} / \mathrm{ml} \mathrm{PGE}_{2}$ and slightly downregulated after incubation with $10 \mu \mathrm{g} / \mathrm{ml}$ $\mathrm{PGE}_{2}$ compared with cells treated with $0 \mu \mathrm{g} / \mathrm{ml} \mathrm{PGE}_{2}$.

$P G E_{2}$ exerts its effect on DC migration by reorganizing the $F$-actin cytoskeleton. Cell migration is dependent on cytoskeletal rearrangements, including the reorganization of the F-actin cytoskeleton (15). Therefore, it was further investigated whether the F-actin cytoskeleton of DCs was affected by $\mathrm{PGE}_{2}$ treatment. The F-actin cytoskeleton was analyzed by immunofluorescence staining using confocal microscopy. The F-actin cytoskeleton in DCs has been reported to attach to the internal surface of the cell membrane (16). As illustrated in Fig. 3A, compared with the control samples, following treatment with low concentration of $\mathrm{PGE}_{2}(2.5 \mu \mathrm{g} / \mathrm{ml})$, the F-actin cytoskeleton was irregularly organized. However, treatment with high concentration of $\mathrm{PGE}_{2}(10 \mu \mathrm{g} / \mathrm{ml})$ induced the arrangement of the F-actin cytoskeleton into regular circles. The method of $\mathrm{Hu}$ et al (16) was used to detect the formation of filopodia in DCs, according to which the number of cell protrusions was calculated. As depicted in Fig. 3B, the number of filopodia on the surface of DCs was decreased following culture of DCs in media containing $10 \mu \mathrm{g} / \mathrm{ml} \mathrm{PGE}_{2}$. By contrast, treatment with $2.5 \mu \mathrm{g} / \mathrm{ml} \mathrm{PGE}{ }_{2}$ increased the number of filopodia on the surface of DCs compared with cells treated with $0 \mu \mathrm{g} / \mathrm{ml} \mathrm{PGE}_{2}$. Via recruiting structural and signaling molecules, paxillin is
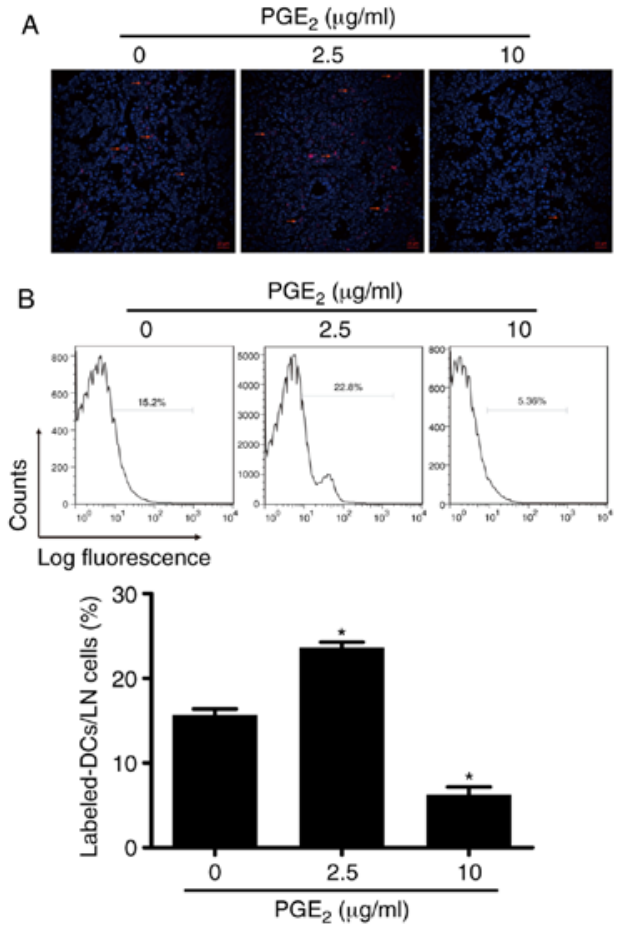

Figure 4. Effect of $\mathrm{PGE}_{2}$ on DC migration in vivo. (A) Immunofluorescence microscopy of DCs in lymph nodes detected by confocal microscopy (original magnification, x400; scale bars, $20 \mu \mathrm{m}$ ). Red staining indicates Qtracker 705-labeled DCs, while blue staining indicates nuclei. (B) FACS profiles of the labeled DCs. Inguinal and popliteal lymph nodes were made into single cell suspensions and the number of labeled DCs was detected by flow cytometry. Data are representative of three independent experiments and are presented as the mean \pm SEM. ${ }^{*} \mathrm{P}<0.05$ vs. $0 \mu \mathrm{g} / \mathrm{ml} \mathrm{PGE}_{2}$. DC, dendritic cell; $\mathrm{PGE}_{2}$, prostaglandin E2; LN, lymph node. 
Table I. GO term analysis of the differentially expressed genes induced by high concentration of prostaglandin E2.

A, Upregulated genes

\begin{tabular}{lrr}
\hline GO term & Gene number & Q-value \\
\hline GO:0048870 'cell motility' & 33 & 0.031953 \\
GO:0016477 'cell migration' & 32 & 0.018743 \\
GO:0006935 'chemotaxis' & 20 & 0.002641 \\
GO:0030335 'positive regulation of cell migration' & 17 & 0.011600 \\
GO:2000147 'positive regulation of cell motility' & 17 & 0.015399 \\
GO:0060326 'cell chemotaxis' & 14 & 0.001859 \\
GO:0030595 'leukocyte chemotaxis' & 0.049438 \\
GO:1990266 'neutrophil migration' & 6 & 0.042027 \\
GO:0038089 'positive regulation of cell migration by vascular endothelial growth & 0.033365 \\
factor signaling pathway' & 2 \\
GO:0090063 'positive regulation of microtubule nucleation' & 2 \\
GO:0010968 'regulation of microtubule nucleation' & 2 & 0.021358 \\
\hline
\end{tabular}

B, Downregulated genes

\begin{tabular}{lrr}
\hline GO term & Gene number & Q-value \\
\hline GO:0030334 'regulation of cell migration' & 69 & $3.79 \times 10^{-9}$ \\
GO:2000145 'regulation of cell motility' & 69 & $3.27 \times 10^{-8}$ \\
GO:0048870 'cell motility' & 33 & 0.031953 \\
GO:0060326 'cell chemotaxis' & 33 & $1.80 \times 10^{-7}$ \\
GO:0016477 'cell migration' & 32 & 0.018743 \\
GO:0030595 'leukocyte chemotaxis' & 28 & $3.84 \times 10^{-8}$ \\
GO:0050839 'cell adhesion molecule binding' & 21 & 0.001122 \\
GO:0006935 'chemotaxis' & 20 & 0.002641 \\
GO:0005096 'GTPase activator activity' & 19 & 0.009055 \\
GO:0030335 'positive regulation of cell migration' & 17 & 17 \\
GO:2000147 'positive regulation of cell motility' & 13 & 9.011600 \\
GO:0004896 'cytokine receptor activity' & 0.015399 \\
GO:0003777 'microtubule motor activity' & 0.001157 \\
GO:0048020 'CCR chemokine receptor binding' & 7 & 2 \\
GO:0090063 'positive regulation of microtubule nucleation' & 0.028882 \\
\hline
\end{tabular}

GO, gene ontology.

a multifunctional focal adhesion adaptor protein, which has been reported to serve an important role in cell migration (17). Western blotting was used to analyze the phosphorylation levels of paxillin at Tyr118. As illustrated in Fig. 3C and D, treatment with $10 \mu \mathrm{g} / \mathrm{ml} \mathrm{PGE}_{2}$ reduced the phosphorylation levels of paxillin at Tyr118 in DCs compared with cells treated with $0 \mu \mathrm{g} / \mathrm{ml} \mathrm{PGE}{ }_{2}$. By contrast, treatment with $2.5 \mu \mathrm{g} / \mathrm{ml}$ $\mathrm{PGE}_{2}$ enhanced the phosphorylation levels of paxillin at Tyr118. However, the total protein expression levels of paxillin were not affected by neither of the treatments. Therefore, these results suggested that $\mathrm{PGE}_{2}$ may exert its effect on DC migration by reorganizing the F-actin cytoskeleton.

Validation of the effect of $P G E_{2}$ on DC migration in vivo. The aforementioned experiments demonstrated the modulatory effect of $\mathrm{PGE}_{2}$ on DC migration in vitro. This mechanism was subsequently validated with in vivo experiments using C57BL/6 mice. Both the results from FACS and immunofluorescence analyses revealed that high concentration of $\mathrm{PGE}_{2}(10 \mu \mathrm{g} / \mathrm{ml})$ inhibited DC migration in vivo, which was evidenced by the lower number of labeled DCs observed in the lymph nodes compared with mice injected with $0 \mu \mathrm{g} / \mathrm{ml} \mathrm{PGE}_{2}$-treated DCs (Fig. 4A and B). On the other hand, the higher number of labeled cells obtained following treatment with $2.5 \mu \mathrm{g} / \mathrm{ml} \mathrm{PGE}_{2}$ indicated that DC migration was facilitated by the low concentration of $\mathrm{PGE}_{2}$ in vivo. These results indicated that $\mathrm{PGE}_{2}$ exhibited the same modulatory effect on DC migration both in vivo and in vitro.

Transcriptome analysis of DCs treated with $P G E_{2}$. A transcriptome analysis using RNA-seq was performed, and the datasets 
Table II. GO term analysis of the differentially expressed genes induced by low concentration of prostaglandin E2.

A, Upregulated genes

\begin{tabular}{lrr}
\hline GO term & Gene number & Q-value \\
\hline GO:0044281 'small molecule metabolic process' & 17 & 0.043246 \\
GO:0030335 'positive regulation of cell migration' & 8 & 0.067606 \\
GO:2000147 'positive regulation of cell motility' & 8 & 0.075799 \\
GO:0051272 'positive regulation of cellular component movement' & 4 & 0.078608 \\
GO:0042572 'retinol metabolic process' & 4 & 0.017945 \\
GO:0006720 'isoprenoid metabolic process' & 4 & 0.043305 \\
GO:0016101 'diterpenoid metabolic process' & 3 & 0.030277 \\
GO:0032620 'interleukin-17 production' & 3 & 0.043246 \\
GO:0046460 'neutral lipid biosynthetic process' & 3 & 0.043246 \\
GO:0051973 'positive regulation of telomerase activity' & 3 & 0.043246
\end{tabular}

B, Downregulated genes

\begin{tabular}{lrr}
\hline GO term & Gene number & Q-value \\
\hline GO:0007155 'cell adhesion' & 23 & 23 \\
GO:0022610 'biological adhesion' & 19 & 0.000066 \\
GO:0048870 'cell motility' & 18 & 0.000071 \\
GO:0016477 'cell migration' & 16 & 0.010072 \\
GO:0030334 'regulation of cell migration' & 16 & 0.008858 \\
GO:2000145 'regulation of cell motility' & 15 & 0.000929 \\
GO:0030155 'regulation of cell adhesion' & 12 & 0.001466 \\
GO:0043062 'extracellular structure organization' & 10 & 0.000305 \\
GO:2000147 'positive regulation of cell motility' & 8 & 0.000018 \\
GO:0060326 'cell chemotaxis' & 6 & 0.012432 \\
GO:0050921 'positive regulation of chemotaxis' & 0.005049 \\
\hline
\end{tabular}

GO, gene ontology.

analyzed are presented in Fig. 5A. A total of 9 samples divided into three groups, which represented three different concentrations of $\mathrm{PGE}_{2}$, were included. The correlation between samples is demonstrated in Fig. 5B. Between any two samples, a higher correlation indicated higher similarity of the expression patterns and better biological repeatability. As illustrated in Fig. 5B, the sample correlations within groups were higher compared with those between groups, indicating that the repeatability of samples within each group was satisfactory. A total of 17,707 genes were identified to be co-expressed among all samples (Fig. 5C). In addition, $>300$ uniquely expressed genes were detected in each sample. The gene expression profiles were considered to be differentially expressed when a >1.2-fold change was obtained. The analysis identified 321 upregulated genes and 839 downregulated genes following treatment with $10 \mu \mathrm{g} / \mathrm{ml} \mathrm{PGE}$ (Fig. 5D). Conversely, treatment with $2.5 \mu \mathrm{g} / \mathrm{ml} \mathrm{PGE}{ }_{2}$ resulted in 101 upregulated genes and 134 downregulated genes compared with the $0 \mu \mathrm{g} / \mathrm{ml} \mathrm{PGE}_{2}$ group. As presented in Tables I and II, GO functional term enrichment analysis illustrated that these genes were related to cellular functions, such as 'cell motility', 'cell migration', 'cell chemotaxis' and 'cell adhesion', among others. Furthermore, KEGG signaling pathway enrichment analysis was performed to analyze the relevant signaling pathways of the differentially expressed genes. The results revealed that signaling pathways, including 'cell adhesion molecules', 'MAPK signaling pathway', 'focal adhesion', 'cytokine-cytokine receptor interaction', 'regulation of actin cytoskeleton', 'leukocyte transendothelial migration', 'chemokine signaling pathway' and 'PI3K-Akt signaling pathway', among others, were associated with the differentially expressed genes (Tables III and IV).

\section{Discussion}

$\mathrm{PGE}_{2}$ has been associated with numerous processes resulting in the induction of inflammation (18). $\mathrm{PGE}_{2}$ is usually considered to be a classical pro-inflammatory mediator. For example, Hooper et al (19) described novel pro-inflammatory functions of $\mathrm{PGE}_{2}$ in murine BMDCs, including its ability to inhibit the production of IL-27. However, accumulating evidence has indicated that $\mathrm{PGE}_{2}$ may also exert anti-inflammatory effects. For instance, a previous study has reported that $\mathrm{PGE}_{2}$ exhibited an 


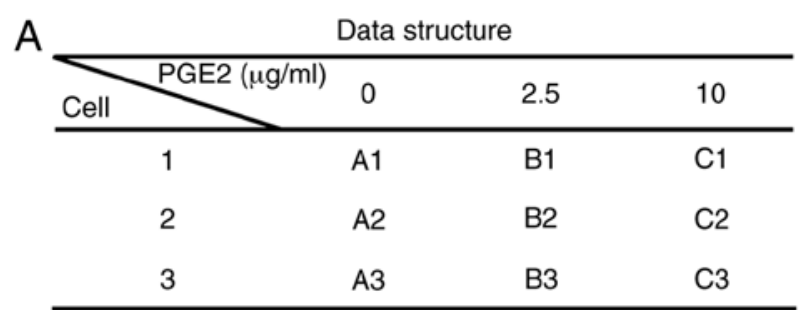

C

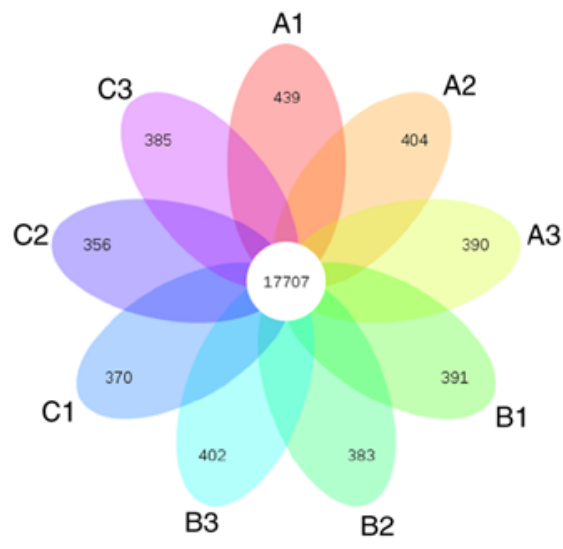

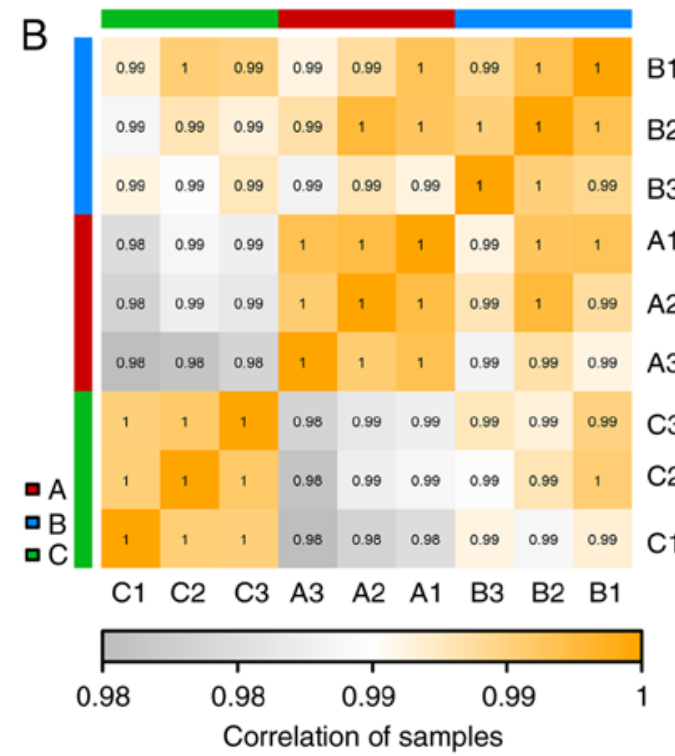

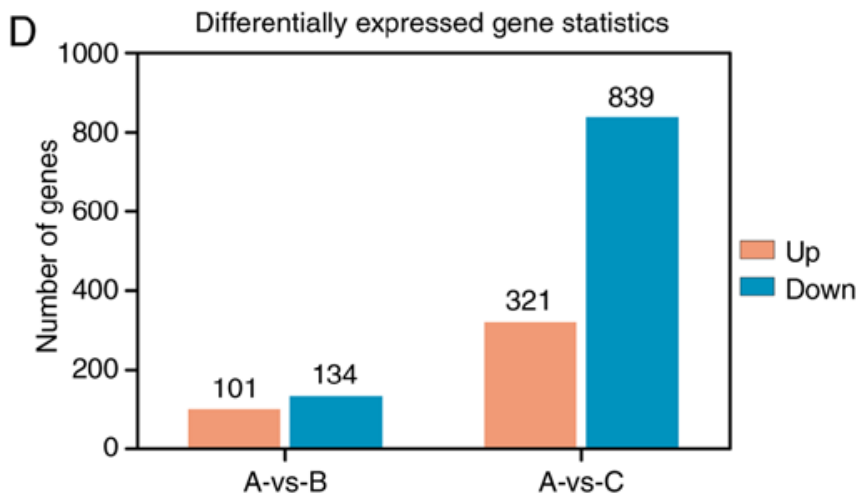

Figure 5. Transcriptome profiling of DCs treated with $\mathrm{PGE}_{2}$. (A) Data structure used in this experiment. Group A was treated with $0 \mu \mathrm{g} / \mathrm{ml}$, Group B with $2.5 \mu \mathrm{g} / \mathrm{ml}$ and Group C with $10 \mu \mathrm{g} / \mathrm{ml} \mathrm{PGE}_{2}$. Each group included three samples. (B) Heatmap of correlation analysis between samples. The color code represents the value of correlation. Yellow color indicates high correlation between samples, and gray color indicates low correlation. (C) Number of common and unique identified genes in each sample. (D) Number of differentially expressed genes identified in DCs treated with different concentrations of PGE . 'A vs B' indicates the differentially expressed genes identified in DCs treated with $2.5 \mu \mathrm{g} / \mathrm{ml} \mathrm{PGE} \mathrm{E}_{2}$. A vs C' indicates the differentially expressed genes identified in DCs treated with $10 \mu \mathrm{g} / \mathrm{ml} \mathrm{PGE}_{2}$. Group A was used as control. A fold change of 1.2 was used to detect differential expression. DC, dendritic cell; PGE 2 , prostaglandin E2.

anti-inflammatory effect by inhibiting cytokine production in human lung macrophages (20). Therefore, it is not surprising that $\mathrm{PGE}_{2}$ has been discovered to serve a dual role in certain modulatory processes. In experimental autoimmune encephalomyelitis, $\mathrm{PGE}_{2}$ has been indicated to facilitate the generation of Th1 and Th17 cells during immunization, but attenuate the invasion of these cells into the brain, thereby protecting the blood brain barrier (21). Moreover, Poloso et al (22) demonstrated that physiologically relevant concentrations of $\mathrm{PGE}_{2}$ suppressed IL-23 production in DCs, while lower concentrations of $\mathrm{PGE}_{2}$ promoted IL-23 production. Notably, $\mathrm{PGE}_{2}$ has been identified to regulate macrophage migration in a concentration-dependent manner (23). Low concentrations of $\mathrm{PGE}_{2}$ have been observed to promote migration of macrophages, while high doses of $\mathrm{PGE}_{2}$ have been indicated to inhibit migration and promote adhesion of macrophages (23). These effects occurred via a similar mechanism as those observed in the present study, except for the fact that a different cell type was used.

As both DCs and macrophages are central cells in the immune system, it is helpful to understand the dual function of
$\mathrm{PGE}_{2}$ in immune regulation. More importantly, these findings have suggested that the applied concentration of $\mathrm{PGE}_{2}$ may be the key in clarifying its actual role. Therefore, a large range of $\mathrm{PGE}_{2}$ concentrations was initially used in the present study to determine their effect on DC migration. In particular, $5 \mu \mathrm{g} / \mathrm{ml}$ $\mathrm{PGE}_{2}$ exhibited an inhibitory effect on DC migration, which was also reported by Baratelli et al (12). To further validate these findings, a higher concentration of PGE2 $(10 \mu \mathrm{g} / \mathrm{ml})$ was used in the experiments of the current study. As expected, $10 \mu \mathrm{g} / \mathrm{ml} \mathrm{PGE}_{2}$ exerted a stronger inhibitory effect on DC migration compared with of $5 \mu \mathrm{g} / \mathrm{ml}$. These results strengthened the hypothesis that DC migration may be inhibited by high concentration of $\mathrm{PGE}_{2}$. In addition, the data of the present study were not only obtained with in vitro experiments, but were also validated in vivo using an animal model, which further supported the hypothesized mechanism.

Numerous molecules and substances that serve important roles in physiological and pathological processes have been demonstrated to exert a dual role (24-31). For example, as a key factor regulating cellular hypoxia, hypoxia inducible factor- $1 \alpha$ $(\mathrm{HIF}-1 \alpha)$ has been reported to upregulate the expression 
Table III. KEGG pathway analysis of the differentially expressed genes induced by high concentration of prostaglandin E2.

A, Upregulated genes

\begin{tabular}{|c|c|c|}
\hline KEGG pathway & Gene number & Q-value \\
\hline 'Cytokine-cytokine receptor interaction' & 12 & 0.115422 \\
\hline 'PI3K-Akt signaling pathway' & 11 & 0.440419 \\
\hline 'MAPK signaling pathway’ & 10 & 0.414593 \\
\hline 'Focal adhesion' & 7 & 0.463380 \\
\hline 'Rap1 signaling pathway' & 5 & 0.756316 \\
\hline 'Chemokine signaling pathway' & 5 & 0.751124 \\
\hline 'Cell adhesion molecules (CAMs)' & 4 & 0.756316 \\
\hline 'Ras signaling pathway' & 4 & 0.886593 \\
\hline 'Antigen processing and presentation' & 3 & 0.729945 \\
\hline 'Leukocyte transendothelial migration' & 2 & 0.886593 \\
\hline 'Regulation of actin cytoskeleton' & 2 & 0.958670 \\
\hline
\end{tabular}

B, Downregulated genes

\begin{tabular}{lcc}
\hline KEGG pathway & Gene number & Q-value \\
\hline 'Cell adhesion molecules (CAMs)' & 20 & 0.000566 \\
'Chemokine signaling pathway' & 20 & 0.003940 \\
'MAPK signaling pathway' & 17 & 0.523913 \\
'Focal adhesion' & 16 & 0.103853 \\
'Ras signaling pathway' & 15 & 0.344020 \\
'Rapl signaling pathway' & 14 & 0.338164 \\
'Antigen processing and presentation' & 14 & 0.000502 \\
'Regulation of actin cytoskeleton' & 12 & 0.592493 \\
'cAMP signaling pathway' & 7 & 0.988183 \\
'Leukocyte transendothelial migration' & 6 & 0.794709 \\
'T cell receptor signaling pathway' & 3 \\
\hline
\end{tabular}

KEGG, Kyoto Encyclopedia of Genes and Genomes.

levels of forkhead box P3 (FOXP3) to positively regulate the differentiation function of regulatory $\mathrm{T}$ cells $(24,25)$. On the other hand, other previous studies have indicated that HIF- $1 \alpha$ negatively regulated the differentiation of regulatory $\mathrm{T}$ cells by promoting the degradation of FOXP3 $(26,27)$. In cancer progression, numerous molecules have been indicated to simultaneously exhibit both tumor suppressive and oncogenic effects, such as yes-associated protein 1 and p21 (RAC1)-activated kinase 6 (28-31). Moreover, PGE $_{2}$ was previously identified to serve a dual role in regulating the migratory ability of macrophages (23).

In our previous study, it was demonstrated that compared with normal cervical tissues, the expression of $\mathrm{PGE}_{2}$ was gradually upregulated in samples of low-grade squamous intraepithelial lesion, high-grade squamous intraepithelial lesion and squamous carcinoma, which was accompanied by the progression of the disease (11). Therefore, an association between the regulation of DC migration by $\mathrm{PGE}_{2}$ and the progression of cervical cancer was hypothesized to exist, based on the results of the current study. In normal cervical tissues and during the early stages of the development of cervical lesions, $\mathrm{PGE}_{2}$ was considered to serve a tumor suppressive role. The low concentration of $\mathrm{PGE}_{2}$ promoted DC migration, which maintained a normal function of the immune response. However, when the disease further developed, the lesion tissues began to continuously synthesize and release $\mathrm{PGE}_{2}$, which resulted in high levels of $\mathrm{PGE}_{2}$. DC migration was subsequently inhibited, thereby altering the normal function of the immune response, which further promoted the development of the disease. The highest concentration of $\mathrm{PGE}_{2}$ detected in the cervical lesion tissues was a 4-fold increase compared with the normal tissues. This may explain why a high concentration of $\mathrm{PGE}_{2}$ is required to inhibit DC migration.

To the best of our knowledge, the present results may provide a novel model of DC migration in response to chemokines, where the presence of a gradient concentration of $\mathrm{PGE}_{2}$ may modulate cytoskeletal reorganization. A number of molecules are considered to serve a role in mediating the effects of $\mathrm{PGE}_{2}$. For example, it has been revealed that when low doses of $\mathrm{PGE}_{2}$ were present during differentiation of DCs, the migration of DCs towards CCL19 and CCL21 was favored $(32,33)$. This process has been 
Table IV. KEGG pathway analysis of the differentially expressed genes induced by low concentration of prostaglandin E2.

A, Upregulated genes

\begin{tabular}{lrr}
\hline KEGG pathway & Gene number & Q-value \\
\hline 'PI3K-Akt signaling pathway' & 5 & 0.170644 \\
'Cytokine-cytokine receptor interaction' & 4 & 0.223721 \\
'Arginine and proline metabolism' & 4 & 0.007759 \\
'Glycerolipid metabolism' & 4 & 0.007759 \\
'Focal adhesion' & 3 & 0.282260 \\
'Rap1 signaling pathway' & 2 & 0.453930 \\
'Ras signaling pathway' & 2 & 0.453930 \\
'Cell adhesion molecules (CAMs)' & 1 & 0.536388 \\
\hline
\end{tabular}

B, Downregulated genes

\begin{tabular}{llr}
\hline KEGG pathway & Gene number & Q-value \\
\hline 'PI3K-Akt signaling pathway' & 7 & 0.217307 \\
'AGE-RAGE signaling pathway in diabetic complications' & 7 & 0.003353 \\
'Chemokine signaling pathway' & 5 & 0.209988 \\
'Focal adhesion' & 4 & 0.321484 \\
'cAMP signaling pathway' & 3 & 0.516267 \\
'Regulation of actin cytoskeleton' & 3 & 0.542349 \\
'Cell adhesion molecules (CAMs)' & 2 & 0.611224 \\
'Antigen processing and presentation' & 2 & 0.467692
\end{tabular}

KEGG, Kyoto Encyclopedia of Genes and Genomes.

suggested to be regulated via the prostaglandin $\mathrm{E}$ receptor (EP)4/cAMP/protein kinase A pathway in a $\mathrm{PGE}_{2}$-dependent manner (34-36). The regulation of cytoskeletal remodeling by $\mathrm{PGE}_{2}$ has been indicated to be mediated by the increase of intracellular cAMP levels following signaling via the EP2 and EP4 receptors, which has been identified by the use of EP receptor agonists. Moreover, both EP2 and EP4 have been suggested to be required for podosome disassembly and focal adhesion formation in DCs following treatment with high concentration of $\mathrm{PGE}_{2}$ (37). However, EP2 has been suggested to mediate the effects of $\mathrm{PGE}_{2}$ in inhibiting the migration of DCs (12). Therefore, future experiments will aim to determine the currently controversial molecular mechanism of $\mathrm{PGE}_{2}$ function.

RNA-seq technology can simultaneously detect the expression of thousands of genes, and profile gene expression in the context of a sample's entire transcriptome. In the present study, to determine the downstream effects of $\mathrm{PGE}_{2}$ on DCs, RNA-seq technology was applied. When analyzing the data of RNA-seq, previous studies have used a threshold value of 2 for the fold change of the differential expression $(38,39)$. However, the current study used a threshold value of 1.2 to screen the differentially expressed genes to the greatest possible extent. It must be noted that the present study presents certain limitations. Firstly, the mRNA and also possibly the protein expression levels of several genes that affect the remodeling of the cytoskeletal reorganization will not change (40). Therefore, these genes cannot be detected and identified as differentially expressed genes using RNA-seq. Examples of such genes include paxillin, vinculin and actin (40). Secondly, the DCs used in the present study were primary cultured cells, which may contain a certain proportion of impure cells $(41,42)$. This may lead to partial interference with the obtained RNA-seq results. Thirdly, the samples used for RNA-seq analysis were collected at a fixed time point following treatment with $\mathrm{PGE}_{2}$. However, it is possible that different genes require distinct treatment times to exhibit differential expression levels, which may exclude certain key molecules from being identified.

In conclusion, the present study used DCs as a model to study the role of $\mathrm{PGE}_{2}$ in cell migration. The findings provided novel insights into the dose-dependent effects of $\mathrm{PGE}_{2}$ as a modulator of actin cytoskeletal reorganization, which is essential for cell migration. Moreover, the results may provide an improved understanding of the mechanisms in different types of malignant disease, such as gynecological tumors, where $\mathrm{PGE}_{2}$ demonstrates pleiotropic functions associated with proliferation, metastasis and invasion.

\section{Acknowledgements}

The authors would like to thank Professor Jiongyu $\mathrm{Hu}$ and Professor Yizhi Peng (Institute of Burn Research, Southwest Hospital, State Key Laboratory of Trauma, Burns and Combined Injury, Third Military Medical University, 
Chongqing, China) for technical assistance in preparing the manuscript.

\section{Funding}

The present study was funded by National Natural Science Foundation of China (grant no. 81272864) and Natural Science Foundation of Chongqing (grant nos. cstc2017shms-zdyfX0043 and cstc2019jcyj-msxmX0445).

\section{Availability of data and materials}

All data generated or analyzed during the present study are included in this published article.

\section{Authors' contributions}

JG and JH designed the study. GD and JH performed the experiments and were major contributors in writing the manuscript. $\mathrm{XZ}, \mathrm{XS}$ and MT assisted with the experiments and data analysis. All authors have read and approved the final manuscript.

\section{Ethics approval and consent to participate}

The present study was approved by the Ethics Committee of Daping Hospital, Army Medical University (Third Military Medical University; Chongqing, China).

\section{Patient consent for publication}

Not applicable.

\section{Competing interests}

The authors declare that they have no competing interests.

\section{References}

1. Qian C and Cao X: Dendritic cells in the regulation of immunity and inflammation. Semin Immunol 35: 3-11, 2018.

2. Banchereau J and Steinman RM: Dendritic cells and the control of immunity. Nature 392: 245-252, 1998.

3. Dong R, Cwynarski K, Entwistle A, Marelli-Berg F Dazzi F, Simpson E, Goldman JM, Melo JV, Lechler RI, Bellantuono I, et al: Dendritic cells from CML patients have altered actin organization, reduced antigen processing, and impaired migration. Blood 101: 3560-3567, 2003.

4. Worbs T, Hammerschmidt SI and Förster R: Dendritic cell migration in health and disease. Nat Rev Immunol 17: 30-48, 2017.

5. Kara PP, Ayhan A, Caner B, Gultekin M, Ugur O, Bozkurt MF, Usubutun A and Uner A: Analysis of dendritic cells in sentinel lymph nodes of patients with endometrial and patients with cervical cancers. Int J Gynecol Cancer 19: 1239-1243, 2009.

6. Saalbach A, Janik T, Busch M, Herbert D, Anderegg U and Simon JC: Fibroblasts support migration of monocyte-derived dendritic cells by secretion of $\mathrm{PGE}_{2}$ and MMP-1. Exp Dermatol 24: 598-604, 2015.

7. Harizi H: Reciprocal crosstalk between dendritic cells and natural killer cells under the effects of $\mathrm{PGE}_{2}$ in immunity and immunopathology. Cell Mol Immunol 10: 213-221, 2013.

8. Yen JH, Khayrullina T and Ganea D: $\mathrm{PGE}_{2}$-induced metalloproteinase-9 is essential for dendritic cell migration. Blood 111: 260-270, 2008.

9. Scandella E, Men Y, Legler DF, Gillessen S, Prikler L, Ludewig B and Groettrup M: CCL19/CCL21-triggered signal transduction and migration of dendritic cells requires prostaglandin E2. Blood 103: 1595-1601, 2004.
10. Rubio MT, Means TK, Chakraverty R, Shaffer J, Fudaba Y, Chittenden M, Luster AD and Sykes M: Maturation of human monocyte-derived dendritic cells (MoDCs) in the presence of prostaglandin E2 optimizes CD4 and CD8 T cell-mediated responses to protein antigens: Role of $\mathrm{PGE}_{2}$ in chemokine and cytokine expression by MoDCs. Int Immunol 17: 1561-1572, 2005.

11. Huang J, Diao G, Zhang Q, Chen Y, Han J and Guo J: E6-regulated overproduction of prostaglandin E2 may inhibit migration of dendritic cells in human papillomavirus 16-positive cervical lesions. Int J Oncol 56: 921-931, 2020.

12. Baratelli FE, Heuzé-Vourc'h N, Krysan K, Dohadwala M, Riedl K, Sharma S and Dubinett SM: Prostaglandin E2-dependent enhancement of tissue inhibitors of metalloproteinases-1 production limits dendritic cell migration through extracellular matrix. J Immunol 173: 5458-5466, 2004.

13. Lutz MB, Kukutsch N, Ogilvie AL, Rössner S, Koch F, Romani N and Schuler G: An advanced culture method for generating large quantities of highly pure dendritic cells from mouse bone marrow. J Immunol Methods 223: 77-92, 1999.

14. Han P, Hanlon D, Sobolev O, Chaudhury R and Edelson RL: Ex vivo dendritic cell generation-A critical comparison of current approaches. Int Rev Cell Mol Biol 349: 251-307, 2019.

15. Burns S, Thrasher AJ, Blundell MP, Machesky L and Jones GE: Configuration of human dendritic cell cytoskeleton by Rho GTPases, the WAS protein, and differentiation. Blood 98: 1142-1149, 2001.

16. Hu ZQ, Xue H, Long JH, Wang Y, Jia Y, Qiu W, Zhou J, Wen ZY, Yao WJ and Zeng Z: Biophysical properties and motility of human mature dendritic cells deteriorated by vascular endothelial growth factor through cytoskeleton remodeling. Int $\mathrm{J}$ Mol Sci 17: 1756, 2016

17. López-Colomé AM, Lee-Rivera I, Benavides-Hidalgo R and López E: Paxillin: A crossroad in pathological cell migration. J Hematol Oncol 10: 50, 2017.

18. Nakanishi $M$ and Rosenberg DW: Multifaceted roles of $\mathrm{PGE}_{2}$ in inflammation and cancer. Semin Immunopathol 35: 123-137, 2013.

19. Hooper KM, Yen JH, Kong W, Rahbari KM, Kuo PC Gamero AM and Ganea D: Prostaglandin E2 inhibition of IL-27 production in murine dendritic cells: A novel mechanism that involves IRF1. J Immunol 198: 1521-1530, 2017.

20. Gill SK, Yao Y, Kay LJ, Bewley MA, Marriott HM and Peachell PT: The anti-inflammatory effects of $\mathrm{PGE}_{2}$ on human lung macrophages are mediated by the $\mathrm{EP}_{4}$ receptor. $\mathrm{Br}$ J Pharmacol 173: 3099-3109, 2016.

21. Esaki Y, Li Y, Sakata D, Yao C, Segi-Nishida E, Matsuoka T, Fukuda $\mathrm{K}$ and Narumiya $\mathrm{S}$ : Dual roles of $\mathrm{PGE}_{2}-\mathrm{EP}_{4}$ signaling in mouse experimental autoimmune encephalomyelitis. Proc Natl Acad Sci USA 107: 12233-12238, 2010.

22. Poloso NJ, Urquhart P, Nicolaou A, Wang J and Woodward DF: $\mathrm{PGE}_{2}$ differentially regulates monocyte-derived dendritic cell cytokine responses depending on receptor usage $\left(\mathrm{EP}_{2} / \mathrm{EP}_{4}\right)$. Mol Immunol 54: 284-295, 2013.

23. Osma-Garcia IC, Punzón C, Fresno M and Díaz-Muñoz MD: Dose-dependent effects of prostaglandin E2 in macrophage adhesion and migration. Eur J Immunol 46: 677-688, 2016.

24. Clambey ET, McNamee EN, Westrich JA, Glover LE, Campbell EL, Jedlicka P, de Zoeten EF, Cambier JC, Stenmark KR, Colgan SP and Eltzschig HK: Hypoxia-inducible factor-1 alpha-dependent induction of FoxP3 drives regulatory T-cell abundance and function during inflammatory hypoxia of the mucosa. Proc Natl Acad Sci USA 109: E2784-E2793, 2012.

25. Flück K, Breves G, Fandrey J and Winning S: Hypoxia-inducible factor 1 in dendritic cells is crucial for the activation of protective regulatory $\mathrm{T}$ cells in murine colitis. Mucosal Immunol 9: 379-390, 2016.

26. Dang EV, Barbi J, Yang HY, Jinasena D, Yu H, Zheng Y, Bordman Z, Fu J, Kim Y, Yen HR, et al: Control of T(H)17/T(reg) balance by hypoxia-inducible factor 1. Cell 146: 772-784, 2011.

27. Lee JH, Elly C, Park Y and Liu YC: E3 ubiquitin ligase VHL regulates hypoxia-inducible factor- $1 \alpha$ to maintain regulatory $\mathrm{T}$ cell stability and suppressive capacity. Immunity 42 : 1062-1074, 2015

28. Shibata M, Ham K and Hoque MO: A time for YAP1: Tumorigenesis, immunosuppression and targeted therapy. Int J Cancer 143: 2133-2144, 2018.

29. Wang G, Lu X, Dey P, Deng P, Wu CC, Jiang S, Fang Z, Zhao K, Konaparthi R, Hua S, et al: Targeting YAP-dependent MDSC infiltration impairs tumor progression. Cancer Discov 6: 80-95, 2016. 
30. Hodgson MC, Deryugina EI, Suarez E, Lopez SM, Lin D, Xue H, Gorlov IP, Wang Y and Agoulnik IU: INPP4B suppresses prostate cancer cell invasion. Cell Commun Signal 12: 61, 2014.

31. Lin H, Rothe K, Chen M, Wu A, Babaian A, Yen R, Zeng J, Ruschmann J, Petriv OI, O'Neill K, et al: The miR-185/PAK6 axis predicts therapy response and regulates survival of drug-resistant leukemic stem cells in CML. Blood 136: 596-609, 2020.

32. De Laere M, Berneman ZN and Cools N: To the brain and back: Migratory paths of dendritic cells in multiple sclerosis. J Neuropathol Exp Neurol 77: 178-192, 2018.

33. Seyfizadeh N, Muthuswamy R, Mitchell DA, Nierkens S and Seyfizadeh N: Migration of dendritic cells to the lymph nodes and its enhancement to drive anti-tumor responses. Crit Rev Oncol Hematol 107: 100-110, 2016.

34. Weinlich R, Bortoluci KR, Chehab CF, Serezani CH, Ulbrich AG, Peters-Golden M, Russo $M$ and Amarante-Mendes GP: TLR4/MYD88-dependent, LPS-induced synthesis of $\mathrm{PGE}_{2}$ by macrophages or dendritic cells prevents anti-CD $\mathrm{CD}_{3}$-mediated $\mathrm{CD}_{95} \mathrm{~L}$ upregulation in T cells. Cell Death Differ 15: 1901-1909, 2008.

35. Yokoyama U, Iwatsubo K, Umemura M, Fujita T and Ishikawa Y: The prostanoid EP4 receptor and its signaling pathway. Pharmacol Rev 65: 1010-1052, 2013

36. Regan JW: EP2 and EP4 prostanoid receptor signaling. Life Sci 74: 143-153, 2003

37. van Helden SF, Oud MM, Joosten B, Peterse N, Figdor CG and van Leeuwen FN: $\mathrm{PGE}_{2}$-mediated podosome loss in dendritic cells is dependent on actomyosin contraction downstream of the RhoA-Rho-kinase axis. J Cell Sci 121: 1096-1106, 2008.
38. Schurch NJ, Schofield P, Gierliński M, Cole C, Sherstnev A, Singh V, Wrobel N, Gharbi K, Simpson GG, Owen-Hughes T, et al: How many biological replicates are needed in an RNA-seq experiment and which differential expression tool should you use? RNA 22: 839-851, 2016.

39. Xi WD, Liu YJ, Sun XB, Shan J, Yi L and Zhang TT: Bioinformatics analysis of RNA-seq data revealed critical genes in colon adenocarcinoma. Eur Rev Med Pharmacol Sci 21: 3012-3020, 2017

40. Witteck A, Yao Y, Fechir M, Förstermann U and Kleinert H: Rho protein-mediated changes in the structure of the actin cytoskeleton regulate human inducible NO synthase gene expression. Exp Cell Res 287: 106-115, 2003.

41. Meyer-Wentrup F and Burdach S: Efficacy of dendritic cell generation for clinical use: Recovery and purity of monocytes and mature dendritic cells after immunomagnetic sorting or adherence selection of CD14 $4^{+}$starting populations. J Hematother Stem Cell Res 12: 289-299, 2003.

42. Marques GS, Silva Z and Videira PA: Antitumor efficacy of human monocyte-derived dendritic cells: Comparing effects of two monocyte isolation methods. Biol Proced Online 20: 4, 2018.

(i) () This work is licensed under a Creative Commons Attribution-NonCommercial-NoDerivatives 4.0 International (CC BY-NC-ND 4.0) License. 